\title{
The Pharmacodynamics, Pharmacokinetics, and Safety of Arhalofenate in Combination with Febuxostat When Treating Hyperuricemia Associated with Gout
}

\author{
Alexandra S. Steinberg, Bradley D. Vince, Yun-Jung Choi, Robert L. Martin, \\ Charles A. McWherter, and Pol F. Boudes
}

ABSTRACT. Objective. Arhalofenate (ARH), in development for gout, has uricosuric and anti-flare activities. ARH plus febuxostat (FBX) were evaluated in subjects with gout for serum uric acid (SUA) lowering, drug interaction, and safety.

Methods. Open phase II trial in gout volunteers (NCT02252835). Cohort 1 received ARH $600 \mathrm{mg}$ for 2 weeks, followed by sequential 1-week co-administration of FBX $80 \mathrm{mg}$ followed by $40 \mathrm{mg}$. FBX $40 \mathrm{mg}$ was continued alone for 2 weeks. Cohort 2 received ARH $800 \mathrm{mg}$ for 2 weeks, followed by sequential 1-week co-administration of FBX $40 \mathrm{mg}$ followed by $80 \mathrm{mg}$. FBX $80 \mathrm{mg}$ was continued alone for 2 weeks. SUA, its fractional excretion (FEUA), and plasma oxypurines were assessed. Pharmacokinetics of FBX and ARH were determined alone and in combination for cohort 2.

Results. Baseline mean SUA was $9.4 \mathrm{mg} / \mathrm{dl}$ for cohort $1(\mathrm{n}=16)$ and $9.2 \mathrm{mg} / \mathrm{dl}$ for cohort $2(\mathrm{n}=16)$. The largest SUA decrease (63\%) was observed with ARH $800 \mathrm{mg}+$ FBX $80 \mathrm{mg}$, with all subjects reaching SUA $<6 \mathrm{mg} / \mathrm{dl}$ and $93 \%<5 \mathrm{mg} / \mathrm{dl}$. The area under the curve $(\mathrm{AUC})_{(0-\mathrm{t})}$ of $\mathrm{ARH}$ acid + FBX/ARH acid was $108 \%$. The AUC $_{(0-\mathrm{t})}$ of FBX + ARH acid/FBX was $87 \%$. As expected, FBX increased oxypurines and increases were unaffected by ARH co-administration. Baseline FEUA were low $(3.5 \%-4.6 \%)$ and ARH increased them toward normal without overexcretion of UA. ARH was well tolerated and appeared safe.

Conclusion. ARH and FBX lowered SUA by complementary mechanisms. The combination provided greater decreases than each drug alone. The combination was well tolerated and appeared safe. Trial registration: NCT02252835. (First Release December 15 2016; J Rheumatol 2017;44:374-9; doi:10.3899/jrheum.161062)

Key Indexing Terms:

ARHALOFENATE

ANTIINFLAMMATORY

Gout is the most common inflammatory arthritis ${ }^{1}$. Guidelines ${ }^{2,3}$ recommend a xanthine oxidase inhibitor as urate-lowering therapy (ULT) to bring serum uric acid (SUA) to the target of $<6 \mathrm{mg} / \mathrm{dl}$. If the target is not achieved, guidelines recommend adding a uricosuric. Studies have shown that, with the commonly prescribed doses of xanthine oxidase inhibitors, the majority of patients do not achieve their SUA targets $^{4,5}$. An additional issue is that when ULT treatment is initiated, or resumed, gout flares worsen ${ }^{6,7,8}$. This paradoxical effect is one of the most significant barriers to adherence to ULT $^{9}$. Therefore, guidelines ${ }^{3,10}$ recommend that patients initiating ULT take antiinflammatory compounds such as

From CymaBay Therapeutics Inc., Newark, California; Vince and Associates, Overland Park, Kansas, USA.

A.S. Steinberg, MD, PhD, CymaBay Therapeutics Inc.; B.D. Vince, DO, Vince and Associates; Y.J. Choi, PhD, CymaBay Therapeutics Inc.; R.L. Martin, PhD, CymaBay Therapeutics Inc.; C.A. McWherter, PhD, CymaBay Therapeutics Inc.; P.F. Boudes, MD, CymaBay Therapeutics Inc.

Address correspondence to Dr. P.F. Boudes, CymaBay Therapeutics, Inc., 7999 Gateway Blvd., Suite 130, Newark, California 94560, USA.

E-mail:pboudes@cymabay.com

Full Release Article. For details see Reprints/Permissions at jrheum.org. Accepted for publication November 4, 2016.

$\begin{array}{cr}\text { FEBUXOSTAT } & \text { URICOSURIC } \\ \text { URIC ACID } & \text { GOUT }\end{array}$

colchicine, systemic corticosteroids, or nonsteroidal antiinflammatory drugs (NSAID) for flare prophylaxis. These antiinflammatories are themselves poorly tolerated, potentially unsafe, and contraindicated in many patients with gout $^{11}$. Thus, there is a pressing need for new gout treatments that provide better SUA and flare controls.

Arhalofenate (ARH) is a novel dual-acting drug that defines a new class of gout therapy called urate-lowering anti-flare therapy ${ }^{12}$. It lowers SUA by blocking the tubular reabsorption of uric acid (UA) by URAT-1 and reduces gout flares by blocking the urate crystal-stimulated release of interleukin $1 \beta$ (IL-1 $\beta)^{13,14}$. IL-1 $\beta$ is the key cytokine that triggers gout flares ${ }^{15}$ and specifically blocking it reduces gout flares ${ }^{16}$. Thus, by both lowering SUA and preventing flares, ARH has the potential to simplify the treatment of gout and improve its management.

Our phase II study was designed to evaluate the SUA-lowering of ARH when combined with FBX, to evaluate the potential for a drug interaction, and to assess the tolerability and safety of both drugs when used alone and in combination. The inhibition of xanthine oxidase by FBX was assessed by measuring the plasma oxypurines, xanthine, and

Personal non-commercial use only. The Journal of Rheumatology Copyright ( $)$ 2017. All rights reserved. 
hypoxanthine. The uricosuric action of ARH was assessed by measuring the fractional excretion of UA (FEUA). FEUA measurements were also intended to evaluate hyperuricosuria, a phenomenon linked to acute urate nephropathy ${ }^{17,18}$.

\section{MATERIALS AND METHODS}

The study (NCT02252835/CB102-21426) was conducted in accordance with the Declaration of Helsinki and Good Clinical Practices. The protocol was cleared by US Regulatory Authority and approved by the study center's Institutional Review Board. All volunteers provided written informed consent.

Ours was a 12-week, single-center, randomized, open-label phase II study with 2 parallel cohorts. After a screening of up to 4 weeks, subjects entered a treatment period of 6 weeks followed 2 weeks later by an end-of-study visit. Subjects who successfully completed screening were enrolled into either a nonpharmacokinetic (non-PK) cohort $(n=16)$ or a PK cohort $(\mathrm{n}=16)$.

Volunteers, 18 to 75 years of age, with a diagnosis of gout according to the American College of Rheumatology criteria ${ }^{19}$ and an SUA $\geq 7.5 \mathrm{mg} / \mathrm{dl}$ were eligible. Subjects could be treatment- naive or, if receiving a ULT, they must agree to discontinue ULT for the duration of our study.

The main exclusion criteria were secondary hyperuricemia, a body mass index $(\mathrm{BMI})>42 \mathrm{~kg} / \mathrm{m}^{2}$, a significant electrocardiogram abnormality, an estimated creatinine clearance $<60 \mathrm{ml} / \mathrm{min}$, an alanine or aspartate aminotransferase (ALT or AST) $>3 \times$ the upper limit of normal (ULN), and any condition(s) that would have compromised the safety of the volunteers or prevented compliance with the protocol.

Additional exclusion criteria were chronic treatment with an NSAID that could not be discontinued, a known hypersensitivity or intolerance to FBX or colchicine, and within 8 weeks of screening the use of CYP $3 \mathrm{~A} 4$ inhibitors, cytotoxic agents, ranolazine, digoxin, theophylline, sulphonylureas, thiazolidinediones, desipramine, atypical antipsychotic agents, loop diuretics, warfarin, or phenytoin.

Women of reproductive potential had to use accepted methods of contraception.

Study treatments. Treatments were oral, once daily. Patients were instructed to self-administer study drugs in the morning at the same time each day without regard to food. ARH was given as 200-mg enteric-coated tablets and FBX as $40 \mathrm{mg}$ or $80 \mathrm{mg}$ tablets. Treatment dose and duration are provided in Table 1. Cohort 1 received ARH $600 \mathrm{mg}$ for 2 weeks followed by sequential 1-week co-administration of FBX $80 \mathrm{mg}$ followed by FBX $40 \mathrm{mg}$. FBX $40 \mathrm{mg}$ was continued alone for 2 weeks. Cohort 2 received ARH $800 \mathrm{mg}$ for 2 weeks, followed by sequential 1-week co-administration of FBX $40 \mathrm{mg}$ followed by FBX $80 \mathrm{mg}$. FBX $80 \mathrm{mg}$ was continued alone for 2 weeks. All patients received colchicine $0.6 \mathrm{mg}$ throughout the treatment period for flare prophylaxis.

Subjects taking a concomitant medication known to influence SUA were required to maintain stable doses. Subjects must have been able to tolerate a short course of oral NSAID and/or steroids to treat a flare.

Study assessments. The PK evaluation was conducted only in the cohort receiving ARH $800 \mathrm{mg}$ because the PK of ARH $600 \mathrm{mg}$ was already well characterized, and if no interaction was demonstrated at $800 \mathrm{mg}$, then it would imply that an interaction at $600 \mathrm{mg}$ would be highly unlikely. The PK for ARH $800 \mathrm{mg}$ was evaluated after dosing for 14 days when steady state had been reached. The PK for the ARH and FBX combination was evaluated after ARH had been dosed for 21 days and FBX $80 \mathrm{mg}$ for 7 days. The PK for FBX $80 \mathrm{mg}$ monotherapy was evaluated on Day 42. Subjects were housed overnight to collect PK and urine samples. Serum samples were collected at $0,0.5,1,1.5,2,4,6,8,12$, and $24 \mathrm{~h}$ after drug administration. $\mathrm{C}_{\max }, \mathrm{T}_{\max }$, area under the curve $(\mathrm{AUC})_{(0-\mathrm{t})}$, and $\mathrm{AUC}_{(0-\mathrm{T})}$ were calculated for $\mathrm{ARH}$ acid, the active form of $\mathrm{ARH}$, and FBX. Urine was collected between 0-6 h (morning), 6-12 h (afternoon), and 12-24 h (night) for FEUA (UA clearance divided by creatinine clearance). Additional trough serum PK were collected on days 8,22 , and 36 .

The time course of the uricosuric effect of ARH was investigated by measuring FEUA on days 0, 3, and 7 in 8 subjects receiving ARH $800 \mathrm{mg}$ monotherapy and had supplementary overnight stays for 24-h serial SUA determination and 24-h urine collection. The urine collection intervals were as described above.

The inhibition of xanthine oxidase by FBX was evaluated with plasma samples for oxypurines (xanthine, hypoxanthine) at baseline and on days 1, $8,15,22,29,36$, and 43 during both monotherapies and combination therapy. Plasma guanine was also determined.

Safety assessments included a complete physical and a 12-lead electrocardiogram. Laboratory tests included standard chemistry and hematology, estimated creatinine clearance, and FEUA.

Study outcomes. The primary objectives were (1) SUA reductions with ARH (600 $\mathrm{mg}$ and $800 \mathrm{mg}$ ) when combined with FBX (40 mg and $80 \mathrm{mg}$ ) as both absolute and percentage reductions from baseline, (2) the percentage of patients achieving the target SUA of $<6 \mathrm{mg} / \mathrm{dl},<5 \mathrm{mg} / \mathrm{dl}$, and $<4 \mathrm{mg} / \mathrm{dl}$, and (3) the potential for any significant interaction between ARH and FBX. Secondary objectives were (1) the SUA reductions for ARH $600 \mathrm{mg}$ and 800 $\mathrm{mg}$ and FBX $40 \mathrm{mg}$ and $80 \mathrm{mg}$ as monotherapies, and (2) the safety and tolerability of ARH when combined with FBX, including serious adverse events (SAE), discontinuations for safety, treatment-emergent adverse events (TEAE), and changes in laboratory variables. An analytical objective was to determine the changes in FEUA resulting from treatment with ARH as monotherapy.

Statistics. A sample of 32 study volunteers was planned (16 per cohort). No formal sample size calculation was done. Summary statistics consisted of mean, median, proportion, and measures of distribution. For the difference in response rates to SUA targets $(<6 \mathrm{mg} / \mathrm{dl},<5 \mathrm{mg} / \mathrm{dl}$, and $<4 \mathrm{mg} / \mathrm{dl})$, the McNemar's exact test and the Fisher's exact test were used for comparisons within and between cohorts, respectively. $\mathrm{P}$ values reflect comparisons versus FBX alone. No adjustments for multiple comparisons were made. Changes in FEUA were analyzed by matched pair Student's t tests. All analyses were conducted with SAS 9.4.

Efficacy, PK, and pharmacodynamics (PD) analyses were performed using all evaluable data. Safety analyses were performed using data from patients receiving at least 1 dose of study drug. For PK, noncompartmental analysis was used (WinNonlin Professional 6.3). To test for the presence of an interaction, an ANOVA was applied to the log-transformed $\mathrm{AUC}_{(0-\mathrm{t})}$, $\mathrm{AUC}_{(0-\mathrm{T})}$, and $\mathrm{C}_{\max }$ values. The $90 \% \mathrm{CI}$ of the test treatment geometric mean of $\mathrm{AUC}_{(0-\mathrm{t})}, \mathrm{AUC}_{(0-\mathrm{T})}$, and $\mathrm{C}_{\max }$ relative to the reference treatment geometric mean (ARH or FBX) were calculated.

\section{RESULTS}

Thirty-two subjects were enrolled and received treatment, with 16 in each cohort. Twenty-nine subjects (90.6\%)

Table 1. Schedule for study dosing and PK sampling.

\begin{tabular}{lcccc}
\hline Cohort & Weeks 1-2 & Week 3 & Week 4 & Weeks 5-6 \\
\hline Non-PK cohort, $\mathrm{n}=16$ & ARH 600 mg & ARH 600 mg + FBX 80 mg & ARH 600 mg + FBX 40 mg & FBX 40 mg \\
PK cohort, $\mathrm{n}=16$ & ARH 800 $\mathrm{mg}^{\dagger}$ & ARH 800 mg + FBX 40 mg & ARH 800 mg + FBX 80 mg & FBX 80 mg \\
\hline
\end{tabular}

$\dagger$ 24-h PK samples collected on Day 14. ${ }^{\ddagger} 24-\mathrm{h}$ PK samples collected on Day 28. ${ }^{\S}$ 24-h PK samples collected on Day 42. PK: pharmacokinetic; ARH: arhalofenate; FBX: febuxostat.

Personal non-commercial use only. The Journal of Rheumatology Copyright $@$ $~ 2017$. All rights reserved 
completed the study. Two subjects in the PK cohort discontinued the study, 1 during Week 4 (ARH $800 \mathrm{mg}$ and FBX $80 \mathrm{mg}$ ) for an AE (worsening hypertension) and 1 during weeks 5-6 (FBX $80 \mathrm{mg}$ ) for poor compliance with procedures. One patient in the non-PK cohort dropped out of the study during Week 4 (ARH $600 \mathrm{mg}$ and FBX $40 \mathrm{mg}$ ) for personal reasons.

Demographics and baseline characteristics were similar between cohorts. Most subjects were men (31/32) and white (28/32). The mean (SD) age was 49.72 (11.7) years. The mean (SD) BMI was $33.58(4.6) \mathrm{kg} / \mathrm{m}^{2}$. The mean (SD) SUA were $9.2(1.0) \mathrm{mg} / \mathrm{dl}$ for the PK cohort and $9.4(1.2) \mathrm{mg} / \mathrm{dl}$ for the non-PK cohort.

Efficacy. The changes in SUA from baseline following sequential treatments in both cohorts are provided in Figure 1. The largest decrease in SUA was observed with the ARH $800 \mathrm{mg}+\mathrm{FBX} 80 \mathrm{mg}$ combination at Week 4 with absolute and percent changes from baseline of $5.8 \mathrm{mg} / \mathrm{dl}$ and $63 \%$, respectively. These changes were significantly greater than those for ARH or FBX alone (weeks 2 and 6, respectively; $\mathrm{p}<0.0001)$. The mean SUA changes from baseline in the ARH $600 \mathrm{mg}+\mathrm{FBX} 80 \mathrm{mg}$ and the ARH $800 \mathrm{mg}+\mathrm{FBX} 40$ mg combinations were similar at Week $3(-54 \%$ and $-55 \%$, respectively).

At the end of each treatment, the percentage of subjects reaching SUA of $<6 \mathrm{mg} / \mathrm{dl},<5 \mathrm{mg} / \mathrm{dl}$, and $<4 \mathrm{mg} / \mathrm{dl}$ for FBX monotherapy and combinations are shown in Table 2. All 14

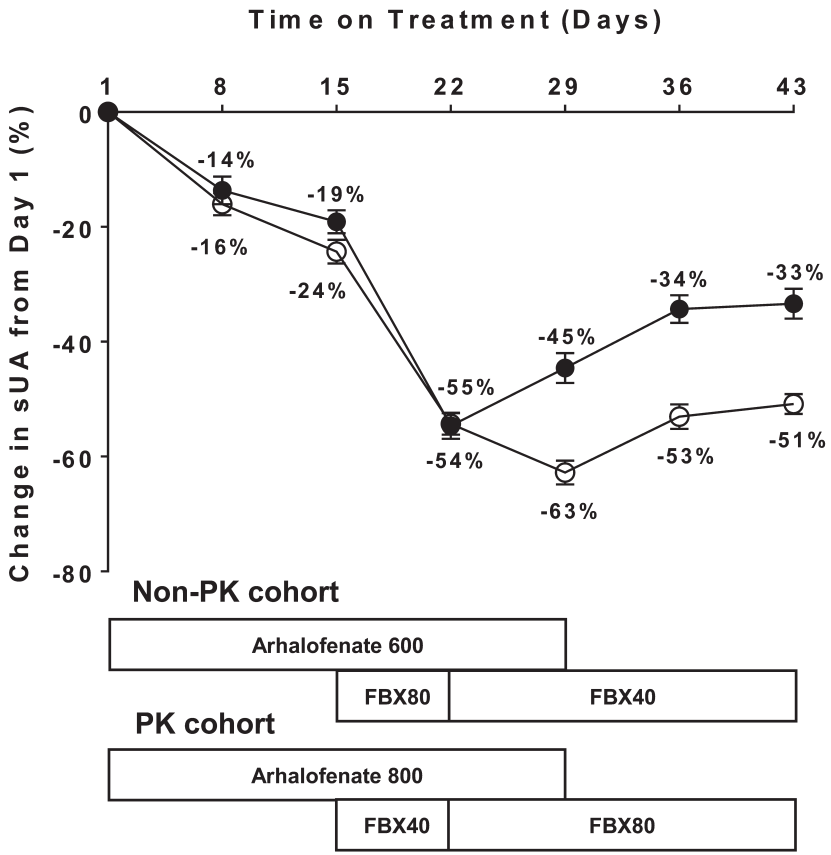

Figure 1. Percent reduction from baseline in SUA. Change in percent change in SUA from Day 1 throughout the study for the PK $(\ominus)$ and the non-PK cohort (-). Mean baseline SUA were $9.2 \mathrm{mg} / \mathrm{dl}$ and $9.4 \mathrm{mg} / \mathrm{dl}$ for the PK and non-PK cohorts, respectively. Patients were dosed according to the regimen shown in Table 1. SUA: serum uric acid; PK: pharmacokinetic; FBX80: febuxostat $80 \mathrm{mg}$; FBX40: febuxostat $40 \mathrm{mg}$. subjects $(100 \%)$ treated with ARH $800 \mathrm{mg}+\mathrm{FBX} 80 \mathrm{mg}$ achieved an SUA of $<6.0 \mathrm{mg} / \mathrm{dl}$ and $13 / 14$ subjects (93\%) achieved an SUA of $<5 \mathrm{mg} / \mathrm{dl}$. Eleven out of 14 subjects (79\%) achieved the target of $<4 \mathrm{mg} / \mathrm{dl}(\mathrm{p}<0.05)$. Overall, $100 \%$ of subjects receiving ARH $800 \mathrm{mg}$, with either $40 \mathrm{mg}$ or $80 \mathrm{mg}$ of FBX, reached an SUA of $<6.0 \mathrm{mg} / \mathrm{dl}$. For subjects receiving ARH $800 \mathrm{mg}$ as monotherapy, SUA decreased gradually over the first 14 days with a decrease from baseline of $1.88 \mathrm{mg} / \mathrm{dl}$ (-24\%; Figure 2). There were minimal intra-day fluctuations in mean SUA when ARH was administered either as monotherapy or in combination with FBX (Figure 2).

All subjects had low FEUA at baseline for the 3 collection intervals (morning, afternoon, and night). Values ranged from $3.5 \%$ to $4.6 \%$ with the lowest values overnight (Figure 3). Treatment with ARH $800 \mathrm{mg}$ increased the mean FEUA during each period on days 3,7 , and 14 (4.5\% to $6.5 \%$, $\mathrm{p}<0.001$ overall). The mean FEUA values were well below the $\mathrm{ULN}^{20}$. Treatment with febuxostat monotherapy decreased FEUA $(3.1 \%)$ relative to baseline, whereas its

Table 2. Percentage of patients achieving target SUA. Values are $\%$ unless otherwise specified.

\begin{tabular}{lcccc}
\hline FBX, mg & ARH, mg & \multicolumn{3}{c}{ Target SUA, mg/dl } \\
& & $<6$ & $<5$ & $<4$ \\
\hline 40 & 0 & 47 & 7 & 0 \\
$40^{\dagger}$ & 600 & 79 & $43 *$ & 7 \\
$40^{\dagger}$ & 800 & $100^{* *}$ & $93 * * *$ & 20 \\
80 & 0 & 93 & 71 & 29 \\
$80^{\ddagger}$ & 600 & 94 & 88 & 31 \\
$80^{\ddagger}$ & 800 & 100 & 93 & $79 *$ \\
\hline
\end{tabular}

$\dagger$ Comparison vs $40 \mathrm{mg} .{ }^{\ddagger} 80 \mathrm{mg}$ FBX monotherapy. $* \mathrm{p}<0.05 . * * \mathrm{p}<0.01$ $* * * \mathrm{p}<0.001$. SUA: serum uric acid; FBX: febuxostat; ARH: arhalofenate.

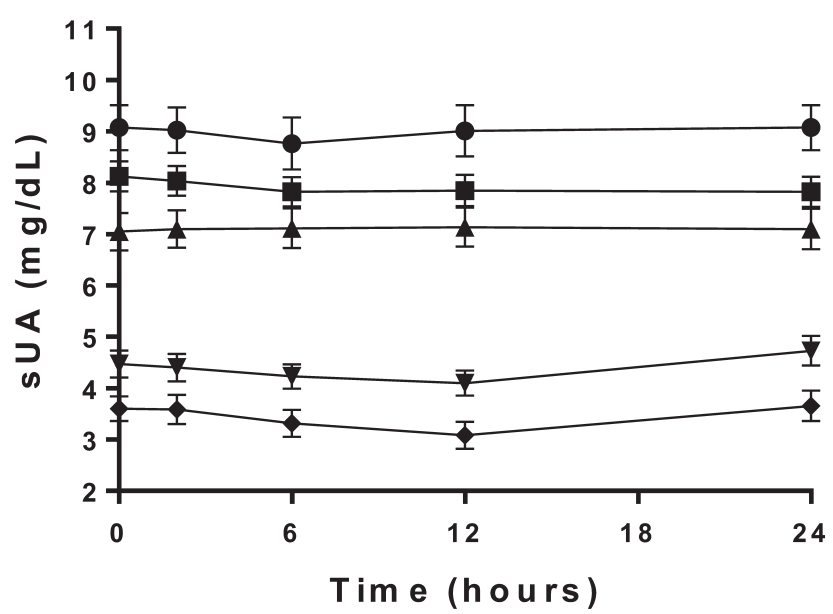

Figure 2. Inter- and intra-day variation of SUA for selected dose combinations of ARH and FBX. Mean inter-day SUA levels during a 24-h sampling period. Assessments were made for a subset of patients in the PK cohort at baseline (@, Day 0, n = 8), ARH $800 \mathrm{mg}(\boldsymbol{\square}$, Day 7, n = 8), ARH $800 \mathrm{mg}$ $(\boldsymbol{\Delta}$, Day 14, n = 8), ARH $800 \mathrm{mg}$ plus FBX $80 \mathrm{mg}(\boldsymbol{\nabla}$, Day 28, n =7), and FBX $80 \mathrm{mg}(\bullet$, Day $42, \mathrm{n}=7)$. Values are mean \pm SD. SUA: serum uric acid; PK: pharmacokinetic; ARH: arhalofenate; FBX: febuxostat. 


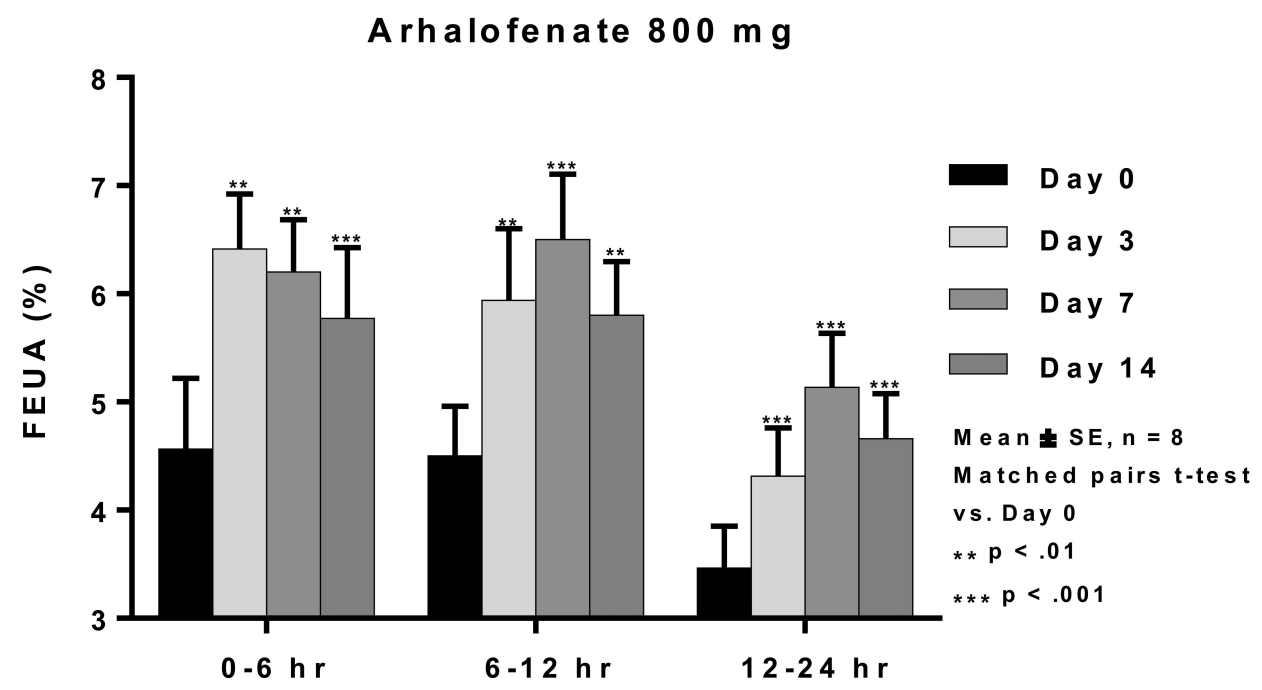

Figure 3. FEUA for $24 \mathrm{~h}$ during treatment with ARH $800 \mathrm{mg}$. FEUA was determined for a subset of the PK cohort of patients treated with ARH $800 \mathrm{mg}$. Uric acid and creatinine concentrations were determined from urine and serum samples and the results used to calculate FEUA. Urine samples were collected over the indicated intervals. FEUA: fractional excretion of uric acid; PK: pharmacokinetic; ARH: arhalofenate.

co-administration with ARH resulted in an increase in FEUA to $4.8 \%$ (data not shown).

The mean (SD) ARH acid $\mathrm{T}_{\max }$ were $5.8(6.3)$ hours and 5.3 (6.3) hours and the $\mathrm{C}_{\max }$ were $140(33) \mu \mathrm{g} / \mathrm{ml}$ and 153 (34) $\mu \mathrm{g} / \mathrm{ml}$ in the absence and presence of FBX, respectively. The $\mathrm{AUC}_{(0-\mathrm{t})}$ was $2960(730) \mu \mathrm{g} \times \mathrm{h} / \mathrm{ml}$ and $3190(870) \mu \mathrm{g} \times$ $\mathrm{h} / \mathrm{ml}$ in the absence and the presence of FBX, respectively. The ratio of $\mathrm{AUC}_{(0-\mathrm{T})}$ geometric means of the combination to ARH alone was $108 \%$ (90\% CI 89-131).

The serum half-life of ARH acid is about $50 \mathrm{~h}$ and sampling was conducted for only $24 \mathrm{~h}$. Therefore, the half-life was estimated at $77 \mathrm{~h}$.

In vivo inhibition of xanthine oxidase increases the concentrations of its substrates xanthine and hypoxanthine ${ }^{21}$. This was indeed observed during treatment with FBX as monotherapy and in combination with ARH (Figure 4). FBX treatment resulted in dose-dependent increases in xanthine (up to 11.5-fold alone and 12-fold in combination with ARH) and hypoxanthine (up to 2.5-fold alone and 2.7-fold in combination with ARH). ARH monotherapy (600 mg and $800 \mathrm{mg}$ ) did not increase xanthine or hypoxanthine. Similar results were seen with guanine (data not shown).

Safety and tolerability. There were no deaths and no SAE reported. A total of 36 TEAE were reported by 23/32 patients $(71.9 \%)$. Nonspecific back pain was the most frequent TEAE in 4/32 subjects (12.5\%): 1 each among those being treated with ARH 800 mg, ARH 600 mg, ARH 600 mg + FBX 40 $\mathrm{mg}$, and FBX $80 \mathrm{mg}$. The majority of AE were mild or moderate in severity. One subject had a worsening of preexisting untreated hypertension while receiving ARH $800 \mathrm{mg}$ and FBX $40 \mathrm{mg}$. The event was considered severe because it required initiation of antihypertensive therapy and led to the patient being removed from the study. This event was unrelated to treatment. No other TEAE were severe or resulted in discontinuation of study drug.

One subject had a TEAE of elevated liver transaminases with an onset at the last study visit. ALT was increased above normal on Day 29, and on Day 43 (end of study visit), the ALT value was $>5 \times$ ULN, and the AST value was $>3 \times$ ULN. The subject's transaminases decreased 2 days after completing dosing with FBX and colchicine. The investigator considered the event to be probably related to FBX, and possibly related to ARH and colchicine.

No subjects had an elevation in serum creatinine $\geq 1.5 \times$ the baseline value or a serum creatinine value greater than the ULN.

\section{DISCUSSION}

The objectives of our study were to evaluate the SUA-lowering of different combinations of ARH and FBX, the safety of the combinations, and the potential for an interaction between drugs. The effect of ARH monotherapy on FEUA was also measured to investigate the potential consequences of the uricosuric activity of ARH on kidney function. An additional objective was to investigate the contributions of each drug in the combination to the SUA lowering through the evaluation of oxypurine levels.

Our study demonstrates that the combination of ARH and FBX has potent SUA-lowering activity that is superior to that of each drug alone. ARH $800 \mathrm{mg}$ combined with either 40 $\mathrm{mg}$ or $80 \mathrm{mg}$ of FBX enabled all subjects to reach an SUA of $<6 \mathrm{mg} / \mathrm{dl}$, the recommended target for patients with uncomplicated gout ${ }^{2,3}$. Further, when ARH $800 \mathrm{mg}$ was administered with FBX $80 \mathrm{mg}$, 93\% achieved an SUA of $<5 \mathrm{mg} / \mathrm{dl}$

Personal non-commercial use only. The Journal of Rheumatology Copyright @ 2017 . All rights reserved. 


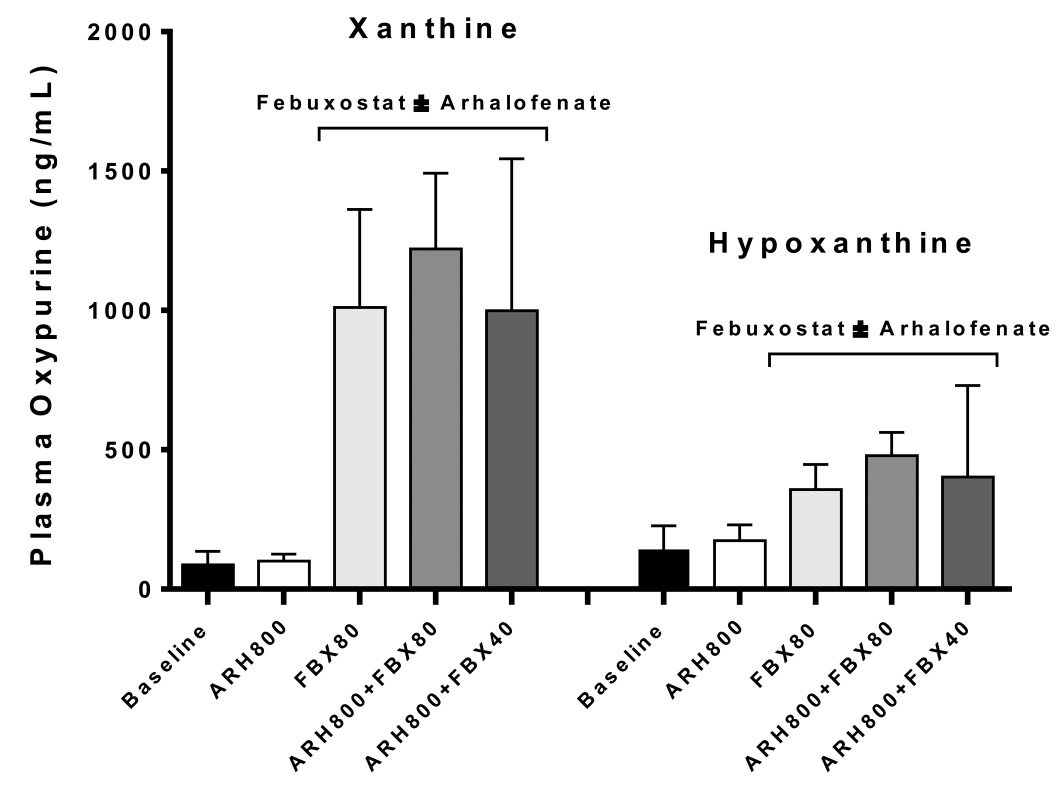

Figure 4. Mean plasma xanthine and hypoxanthine concentrations. Mean plasma concentrations of xanthine and hypoxanthine are shown at baseline and after treatment with ARH, FBX, and their combination. Bars and error bars represent mean \pm SD. ARH: arhalofenate; ARH800: ARH 800 mg; FBX80: febuxostat 80 mg; FBX40: febuxostat 40 mg.

and $79 \%$ an SUA of $<4 \mathrm{mg} / \mathrm{dl}$. Achieving a lower SUA target of $<5 \mathrm{mg} / \mathrm{dl}$ is recommended for gout patients with more advanced disease and large UA burden, clinically exemplified by tophi ${ }^{2}$. In these patients, such a target is necessary to resolve tophi within a reasonable amount of time ${ }^{22}$. Achieving an even lower target, such as $<4 \mathrm{mg} / \mathrm{dl}$, might be clinically relevant because the velocity of tophi reduction is linearly correlated to SUA during therapy: the lower the SUA, the faster the velocity of tophi resolution ${ }^{22}$.

The mechanisms by which ARH and FBX lower SUA were studied using PD markers. For ARH, we evaluated the uricosuric effect by measuring FEUA. For FBX, we evaluated the increases in xanthine and hypoxanthine, both alone and in the presence of ARH. These measurements allowed the SUA-lowering of the 2 compounds to be assessed.

Baseline FEUA were below normal, which is typical for patients with gout ${ }^{20}$. Treatment with ARH, both alone and in combination with FBX, increased FEUA toward the normal range throughout the $24-\mathrm{h}$ period ${ }^{20}$. This was achieved with very limited intra-day variation in SUA levels and UA excretion, a finding that we attribute to the long $(\sim 50 \mathrm{~h})$ plasma half-life of ARH. Therefore, ARH promotes a gradual excretion of UA in the kidney without inducing dangerously high values that might lead to intratubular UA precipitation ${ }^{23}$. This gradual excretion is consistent with the favorable renal safety profile observed to date in clinical studies with $\mathrm{ARH}^{14}$.

Our study demonstrated no significant PK or PD interaction between ARH and FBX. The increases in oxypurines induced by FBX, a consequence of the xanthine oxidase inhibition by the drug ${ }^{21}$, were not altered by the addition of ARH. Thus, the combination provided 2 additive mechanisms, xanthine oxidase inhibition and uricosuric activity, for reducing SUA.

Finally, in our study, the combination of ARH with FBX was well tolerated and appeared safe. This combination fits with current treatment guidelines, which recommend adding a uricosuric to a xanthine oxidase inhibitor ${ }^{2,3}$ for patients with gout who are unable to achieve the SUA target of $<6 \mathrm{mg} / \mathrm{dl}$.

Studies have shown that most patients with gout do not achieve their recommended SUA goals ${ }^{4,5}$. Many continue to experience flare attacks and further joint damage with continued deposition of urate crystals $\mathrm{s}^{4,5}$. A significant barrier to the management of gout is also because of the paradoxical increase in flares when initiating treatment with a $\mathrm{ULT}^{6,7,8,9,24}$.

ARH also possesses an antiinflammatory activity through which it inhibits the urate crystal-stimulated release of IL-1 $\beta^{13}$, a cytokine that is key to triggering gout flares ${ }^{15,16}$. In a mouse air pouch model of urate crystal-induced inflammation, ARH acid (the active form of ARH) suppressed the local release of proinflammatory cytokines, and most notably the release of IL-1 $\beta$. In this model, ARH also prevented the influx of neutrophils at the site of inflammation. In isolated murine macrophages, ARH acid suppressed urate crystal-stimulated release of IL- $1 \beta$ by $83 \%$ and this was associated with a $73 \%$ reduction in the mRNA encoding pro-IL-1 $\beta^{13}$. In a recent phase II study, ARH at a daily dose of $800 \mathrm{mg}$ was shown to significantly reduce the incidence of gout flares by $46 \%$ compared with allopurinol $300 \mathrm{mg}^{14}$.

Personal non-commercial use only. The Journal of Rheumatology Copyright @ 2017 . All rights reserved. 
Upon initiation of combination therapy with ARH and FBX, ARH anti-flare activity would be expected to reduce gout flares commonly observed with ULT $\mathrm{UL}^{6,7,8,24}$. Gout treatment guidelines recommend the use of colchicine, systemic corticosteroids, or NSAID for the prevention and treatment of gout flares ${ }^{3,10}$. While colchicine and NSAID are effective for treating flares, they are poorly tolerated or contraindicated in most patients ${ }^{11}$. A study indicated that $>90 \%$ of patients with gout had at least 1 contraindication to NSAID and systemic steroids, and $>30 \%$ had at least 1 contraindication to colchicine ${ }^{25}$. Thus, the anti-flare activity and SUA-lowering properties of ARH, when used with FBX, could potentially help more patients with gout to reach their SUA goal without triggering ULT-induced flares.

The main limitations of our phase II study were that it was short and was performed in a specialized center with a small number of patients with gout. Hence, the translation of these results to a broader population must be confirmed in larger and longer studies.

Our study demonstrated that patients with gout treated with combinations of ARH (600 mg or $800 \mathrm{mg}$ ) and FBX (40 $\mathrm{mg}$ or $80 \mathrm{mg}$ ) experienced potent reductions in SUA, enabling all patients to achieve the recommended goal of $<$ $6 \mathrm{mg} / \mathrm{dl}$. The combination of ARH $800 \mathrm{mg}$ and FBX $80 \mathrm{mg}$ was particularly effective, allowing the great majority of patients to reduce their SUA below $5 \mathrm{mg} / \mathrm{dl}$, a goal recommended for patients with tophaceous gout. The combination was well tolerated and appeared safe.

\section{REFERENCES}

1. Wertheimer A, Morlock R, Becker MA. A revised estimate of the burden of illness of gout. Curr Ther Res Clin Exp 2013;75:1-4.

2. Khanna D, Fitzgerald JD, Khanna PP, Bae S, Singh MK, Neogi T, et al; American College of Rheumatology. 2012 American College of Rheumatology guidelines for management of gout. Part 1: systematic nonpharmacologic and pharmacologic therapeutic approaches to hyperuricemia. Arthritis Care Res 2012;64:1431-46.

3. Zhang W, Doherty M, Bardin T, Pascual E, Barskova V, Conaghan $\mathrm{P}$, et al; EULAR Standing Committee for International Clinical Studies Including Therapeutics. EULAR evidence based recommendations for gout. Part II: management. Report of a task force of the EULAR Standing Committee For International Clinical Studies Including Therapeutics (ESCISIT). Ann Rheum Dis 2006;65:1312-24.

4. Neogi T, Hunter DJ, Chaisson CE, Allensworth-Davies D, Zhang Y. Frequency and predictors of inappropriate management of recurrent gout attacks in a longitudinal study. J Rheumatol 2006;33:104-9.

5. Kuo CF, Grainge MJ, Mallen C, Zhang W, Doherty M. Rising burden of gout in the UK but continuing suboptimal management: a nationwide population study. Ann Rheum Dis 2015;74:661-7.

6. Borstad GC, Bryant LR, Abel MP, Scroggie DA, Harris MD, Alloway JA. Colchicine for prophylaxis of acute flares when initiating allopurinol for chronic gouty arthritis. J Rheumatol 2004;31:2429-32.

7. Becker MA, Schumacher HR Jr, Wortmann RL, MacDonald PA, Eustace D, Palo WA, et al. Febuxostat compared with allopurinol in patients with hyperuricemia and gout. N Engl J Med 2005;353:2450-61.

8. Schumacher HR Jr, Becker MA, Wortmann RL, Macdonald PA,
Hunt B, Streit J, et al. Effects of febuxostat versus allopurinol and placebo in reducing serum urate in subjects with hyperuricemia and gout: a 28-week, phase III, randomized, double-blind, parallel-group trial. Arthritis Rheum 2008;59:1540-8.

9. Schlesinger N. Treatment of chronic gouty arthritis: it is not just about urate-lowering therapy. Semin Arthritis Rheum 2012; 42:155-65.

10. Khanna D, Khanna PP, Fitzgerald JD, Singh MK, Bae S, Neogi T, et al; American College of Rheumatology. 2012 American College of Rheumatology guidelines for management of gout. Part 2: therapy and antiinflammatory prophylaxis of acute gouty arthritis. Arthritis Care Res 2012;64:1447-61.

11. Stamp LK. Safety profile of anti-gout agents: an update. Curr Opin Rheumatol 2014;26:162-8.

12. Lavan BE, McWherter C, Choi YJ. FRI0403 Arhalofenate, a novel uricosuric agent, is an inhibitor of human uric acid transporters. Ann Rheum Dis 2012;71 Suppl 3:450-1.

13. Choi YJ, Larroca V, Lucman A, Vicena V, Abarca N, Rantz T, et al. Arhalofenate is a novel dual-acting agent with uricosuric and anti-inflammatory properties [abstract]. Arthritis Rheum 2012;64 Suppl 10:1632.

14. Poiley J, Steinberg AS, Choi YJ, Davis CS, Martin RL, McWherter CA, Boudes PF; Arhalofenate Flare Study Investigators. A randomized, double-blind, active- and placebo-controlled efficacy and safety study of arhalofenate for reducing flare in patients with gout. Arthritis Rheumatol 2016;68:2027-34.

15. Martinon F. Mechanisms of uric acid crystal-mediated autoinflammation. Immunol Rev 2010;233:218-32.

16. Mitha E, Schumacher HR, Fouche L, Luo SF, Weinstein SP, Yancopoulos GD, et al. Rilonacept for gout flare prevention during initiation of uric acid-lowering therapy: results from the PRESURGE-2 international, phase 3, randomized, placebo-controlled trial. Rheumatology 2013;52:1285-92.

17. Abraham PA, Halstenson CE, Opsahl JA, Matzke GR, Keane WF. Suprofen-induced uricosuria. A potential mechanism for acute nephropathy and flank pain. Am J Nephrol 1988;8:90-5.

18. Andreucci VE. Different forms of ischemic/toxic acute renal failure in acute renal failure. In: Andreucci VE, editor. Acute renal failure: pathophysiology, prevention, and treatment. New York City: Springer US; 1984:81-6.

19. Wallace SL, Robinson H, Masi AT, Decker JL, McCarty DJ, Yü TF Preliminary criteria for the classification of the acute arthritis of primary gout. Arthritis Rheum 1977;20:895-900.

20. Perez-Ruiz F, Calabozo M, Erauskin GG, Ruibal A, Herrero-Beites AM. Renal underexcretion of uric acid is present in patients with apparent high urinary uric acid output. Arthritis Rheum 2002;47:610-3.

21. Khosravan R, Grabowski BA, Wu JT, Joseph-Ridge N, Vernillet L. Pharmacokinetics, pharmacodynamics and safety of febuxostat, a non-purine selective inhibitor of xanthine oxidase, in a dose escalation study in healthy subjects. Clin Pharmacokinet 2006;45:821-41.

22. Perez-Ruiz F, Calabozo M, Pijoan JI, Herrero-Beites AM, Ruibal A. Effect of urate-lowering therapy on the velocity of size reduction of tophi in chronic gout. Arthritis Rheum 2002;47:356-60.

23. Strom BL, West SL, Sim E, Carson JL. The epidemiology of the acute flank pain syndrome from suprofen. Clin Pharmacol Ther 1989;46:693-9.

24. Becker MA, Schumacher HR, Espinoza LR, Wells AF, MacDonald $P$, Lloyd E, et al. The urate-lowering efficacy and safety of febuxostat in the treatment of the hyperuricemia of gout: the CONFIRMS trial. Arthritis Res Ther 2010;12:R63.

25. Keenan RT, O'Brien WR, Lee KH, Crittenden DB, Fisher MC, Goldfarb DS, et al. Prevalence of contraindications and prescription of pharmacologic therapies for gout. Am J Med 2011;124:155-63.

Personal non-commercial use only. The Journal of Rheumatology Copyright $\subset$ (2017. All rights reserved. 